\title{
UMA ANÁLISE DE DISCURSO SOBRE/DA HOMOSSEXUALIDADE NA IMPRENSA ONLINE: O CASO DA POSSE DE MARCO FELICIANO NA CDHM
}

\author{
A DISCOURSE ANALYSIS OF HOMOSEXUALITY IN THE ONLINE PRESS: THE CASE OF \\ MARCO FELICIANO'S TENURE IN THE CDHM
}

\begin{abstract}
Atílio Butturi Junior
Professor Adjunto da UFFS (campus Erechim) Coordenador da pesquisa Discurso de Gênero, Homoerotismo Formas de Subjetivação.

Jéssica Roberta Sozo

Graduada em História. Acadêmica do curso de Filosofia da UFFS (campus Erechim) Bolsista de Iniciação Científica.
\end{abstract}

RESUMO: Este trabalho tem por objetivo apresentar uma análise do discurso de produção da homossexualidade e de sua contraposição à religiosidade na imprensa online de São Paulo. Metodologicamente, partiu-se da análise do discurso de linha francesa, sobretudo das discussões da arqueogenealogia foucauldiana no que se refere ao dispositivo sexual e à ordenação produtiva dos discursos sobre o corpo e a sexualidade. O corpus é composto por notícias de Marco Feliciano, divulgadas na Folha de São Paulo Online, no período compreendido entre a tomada de posse de Feliciano na Comissão de Direitos Humanos e Minorias (CDHM) como presidente até o decorrer de quinze dias do início de sua presidência. A partir das análises, pode-se verificar no discurso da Folha de São Paulo o embate entre diversas formações discursivas (FD's): uma $F D$ religiosa, que retoma discursos da supostamente da "tradição"; uma FD liberal-meritocrática, que pretende instaurar um regime de avaliação a partir das características do deputado; uma FD de defesa da diversidade, que se enuncia como um discurso de resistência "homossexual" pautada em discursos de democracia, igualdade e laicização do Estado brasileiro. As conclusões apontam para a produção de uma cisão entre um discurso religioso, relacionado a uma memória que remete ao discurso constituinte, e os discursos da sexualidade e do gênero, supostamente de resistência e liberais. PALAVRAS-CHAVE: Comissão de Direitos Humanos e Minorias. Homossexualidade. Discurso jornalístico. Folha de São Paulo

ABSTRACT: The objective of this study was to provide an analysis on the generation of homosexuality and its counter position to religiosity in the Folha de São Paulo Online press. The methods start with an analysis of the French line of address, mainly concerning foucauldian archaeo-genealogy, which discusses sexual provision and the ordinate list of discussions on the body and sexuality. The corpus consists of texts written by Marco Feliciano and published in Folha de São Paulo Online. This was published at the time when Feliciano's candidacy was approved as President of the Human Rights and Minority Commission (HRMC), up until 15 days prior to his Presidency. As a result from the analyses in the Folha de São Paulo discourse, one can observe a collision between many discursive formations (DF): a religious DF that maintains the supposedly 'traditional' discourse; and a liberal-meritocratic DF that intends on establishing a evaluation system based on the deputies' qualities; a Defending Diversity DF that comprises a homosexual resistance in democratic, equality and secularism discourses in the Brazilian State. Conclusions suggest a 
division between one religious discourse, concerning a memory that reminds us of a constituent message, and the other being a supposedly liberal and resistant type gender and sexuality discourse.

KEYWORDS: Commission on Human Rights and Minorities. Homosexuality. Journalistic discourse. Folha de São Paulo

\section{INTRODUÇÃO}

No início de 2013, o Brasil deparou-se com a produção de uma polêmica "polêmica" discursiva, qual seja: os discursos sobre a presidência da Comissão de Direitos Humanos e Minorias (CDHM), que seria ocupada por um deputado que era também pastor evangélico, Marco Feliciano. A imprensa brasileira, a partir de então, foi palco de um embate entre enunciados religiosos, liberais, laicos, produzindo diferenças e organizando discursivamente a produção de identidades e de categorias acerca do desejo, dos sujeitos, do gênero e da sexualidade.

A partir desse contexto, este trabalho interroga, segundo uma perspectiva discursiva, a produção dos discursos sobre/da homossexualidade e sua relação com a produção de outros discursos, como o liberal-meritocrático e o religioso na imprensa brasileira. Para tal análise, o corpus é formado por dezoito textos que circularam no jornal Folha de São Paulo OnLine, no período compreendido entre 6 de março e 7 de abril de 2013.

As análises partem da discussão entabulada pela Análise do Discurso, segundo uma perspectiva que aqui se assume "foucauldiana" e que pretende observar os modos pelos quais são produzidos regimes de dizer e de como estes inauguram uma política microfísica de produção de corporalidades, de normalidade e de abjeção (FOUCAULT, 1993; 2009).

O trabalho, para isso, se organiza em três seções, que se ocupam, respectivamente: da discussão discursiva sobre a construção do gênero e da sexualidade, da descrição das formações discursivas da Folha; da apresentação das relações de memória discursiva, cujo funcionamento será aproximado do conceito de "discurso asseverado". Finalmente, as "Considerações Finais" trazem reflexões breves sobre o itinerário do artigo e as perspectivas de pesquisa.

\section{A HOMOSSEXUALIdAde E A RELIGIÃO: ANÁlise DE UM EMBATE DISCURSIVO}

Ao tratar sobre homossexualidade, faz-se necessário compreender primariamente, o que se entende por sexo e, a partir daí, estabelecer uma discussão com a teoria contemporânea de gênero. Desta forma, Costa $(1995$, p.93) considera: “[...] o sexo é um nome dado a coisas diversas que aprendemos a reconhecer como sexuais de diversas maneiras...". Para o autor, a conceituação do que é sexual é uma questão de hábito linguístico. Partindo disso, diferentes povos podem ter diferentes concepções sobre tal assunto em decorrência da cultura e o hábito que desenvolvem e mantêm. Neste sentido, Costa (1995, p.94) afirma:

[...] existem culturas onde o que reconhecemos como sendo atos sexuais não exigem a noção de sexo como alguma coisa diferente e heterogênea às práticas sexuais. Aquilo que, entre nós, é o fator comum a todos os atos sexuais, ou seja, o que pensamos que uniformiza, unifica e identifica os 
atos sexuais como sendo qualquer coisa da ordem do sexo podem inexistir em certas sociedades. (Grifo do autor).

A ideia que Costa defende para explicar primeiramente o sexo e posteriormente a homossexualidade consiste na efetivação e reprodução de costumes de uma determinada cultura. Sobre isso, o autor destaca os costumes enraizados pelos quais a mulher, até o século XVIII, foi considerada inferior ao homem. Costumes tais, que eram mantidos a partir da sexualidade dominante conceituada one-sex model.

Laqueur (1989, apud COSTA, 1995, p. 100) demonstra o processo arqueológico de produção do conceito de sexo. Ele afirma: "No one-sex model que dominou o pensamento anatômico por dois milênios, a mulher era entendida com sendo um homem invertido. $\mathrm{O}$ útero era o escroto feminino, os ovários eram os testículos, a vulva um prepúcio e a vagina era um pênis". Não havia, portanto, uma divisão da sexualidade entre o sexo feminino e feminino. A partir do século XVIII, uma nova concepção de sexualidade surge: o two-sex model, que parte, conforme Costa (1995, p.101) do princípio de que existe um dimorfismo radical e original da sexualidade. Costa (1995, p.104, grifos do autor) considera:

[...] a diferença entre mulheres e homens era percebida; só não era explicada pela diferença originária de sexos. $\mathrm{O}$ que chamamos sexo, hoje, era a palavra usada para designar apenas os órgãos reprodutores. [...] A forma cultural de distinguir os gêneros masculino e feminino dispensava o recurso à diferença dos sexos. E, ao contrário do que se pensa habitualmente, não foi o estabelecimento da diferença dos sexos que condicionou o lugar social, moral e psicológico da mulher; foi a rediscussão de seu novo estatuto social que deu origem à diferença de sexos como a conhecemos. A formação da nova imagem da mulher nos séculos XVIII, e sobretudo XIX, trouxe à tona a rediscussão da diferença de gêneros. Desta rediscussão surgiu a ideia da diferença de sexos entendida como bissexualidade original e não como hierarquização de funções de um só sexo fisio-anatômico.

Precedendo a análise, é mister que se retome a problemática da sexualidade discursivamente constituída. Foucault (2009) defende a tese de que há, a partir do século XVII, no Ocidente, um modo específico de colocar o prazer em discurso: o dispositivo da sexualidade, que atua como um poder regulamentador, cria métodos de disciplinar e produzir formas de subjetivação e normatização. O mesmo Foucault (1993), a partir da discussão do dispositivo da sexualidade e suas estratégias de produção de subjetividades, entende que, ao contrário do que se postula, não há uma relação ontológica entre o sexo e o sujeito, mas um dispositivo que engendra um discurso onde o comportamento sexual é constantemente ligado à verdade do sujeito. Segundo ele: "O sexo sempre foi o núcleo onde se aloja, juntamente com o devir da nossa espécie, nossa 'verdade' de sujeito humano". (FOUCAULT, 1993, p. 229-230).

Da perspectiva arqueológica, essa tomada do sexo pelo discurso seria uma típica produção dos discursos ocidentais. Assim, em A Vontade de Saber, Michel Foucault parte inicialmente da negação hipótese de um viés repressivo para a sexualidade é descreve como ela passa a ser produzida, exaustivamente e via discurso, no decorrer dos séculos XVII, XVIII e XIX. O discurso sobre uma "sexualidade", antes quase inexistente e fadado ao silêncio, passa, a partir do século XVII, ainda que com possível controle de enunciação, a uma verdadeira explosão discursiva. Foucault (2009) considera o mecanismo de criação do que chama de "dispositivo 
sexual" uma evolução da pastoral católica: passa-se da anterior confissão, que garantia o silêncio do discurso, para a incitação aos discursos.

Em contrapartida à confissão, na qual era mantido um discurso unitário sobre o sexo, surge, a partir do século XVIII, uma incitação ao discurso que acaba por resultar numa grande multiplicidade de discursos. A multiplicidade de variados discursos permitiu com que o sexo fosse alvo de diferentes áreas de conhecimento, e que cada uma delas mantivesse e o considerasse de acordo com o seu discurso. Deste modo, Foucault (2009, p.43) considera: “A proliferação de discursos acabou por multiplicar as condenações judiciárias das perversões menores e logo a associação da irregularidade sexual como doença mental".

$\mathrm{Na}$ discussão atual sobre a sexualidade e os gêneros, as posições foucauldianas configuram uma espécie de solo comum de debates. Seguindo tal "tradição", Butturi Junior (2012, p.25) ressalta a inexistência de uma realidade fora do dispositivo sexual responsável por salvaguardar apenas uma espécie de indivíduo e um mesmo modo de experenciar o comportamento sexual. Ao problematizar a produção da homossexualidade no discurso, seguindo as teses propostas por Judith Butler, Butturi Junior (2012) afirma:

[...] o sexo é um ideal regulatório cuja materialização é imposta: esta materialização ocorre (ou deixa de ocorrer) através de certas práticas altamente reguladas. Em outras palavras, o sexo é um construto ideal que é forçosamente materializado através do temo. Ele não é um simples fato ou a condição estática de um corpo, mas um processo pelo qual as normas regulatórias materializam o sexo e produzem essa materialização através de uma reiteração forçada destas normas. O fato de que essa reiteração seja necessária é um sinal de que a materialização não é nunca totalmente completa, que os corpos não se conformam, nunca, completamente, às normas pelas quais sua materialização é imposta.

Na esteira desestabilização da relação ontológica, Butler (2003) considera que o sexo é categoria normativa que funciona como uma prática regulatória, seja para produzir os corpos que se governa, seja para viabilizar a existência do sujeito como "domínio da inteligibilidade cultural" (BUTLER, 2003, p. 155). Nesse "domínio", cabe notar, nos textos analisados na próxima seção, como cada tomada de posição (liberal ou petencostal) exige uma série de compromissos ontológicos e uma ordenação distinta de objeto (no caso, o gênero e a sexualidade), de conceitos e de estratégias de subjetivação (quem pode dizer, se responsabilizar, construir o verdadeiro sobre a moral sexual atual).

Partindo desse princípio, pode-se considerar que o sexo e o gênero assumem papeis variáveis de acordo com culturas e sociedades específicas e nenhum deles pode ser tomado como precedente ou a priori. A relatividade de ambos os conceitos e dos objetos a eles associados exige que se pense numa relativização numa constante produção-transformação que levem em conta as exigências dos dispositivos sexuais e permita, na relação entre poderes, saberes e sujeitos - que se construam alternativas de resistências e novas modalidade de entender a multiplicidade que envolve os corpos e suas práticas de prazer no Ocidente.

É, pois, do entendimento dos gêneros em sua multiplicidade discursiva e da sexualidade como produção discursiva que se analisarão os discursos na próxima seção. 


\section{AS FORMAÇÕES DISCURSIVA NA FOLHA}

Como afirma Foucault (2008), em A Arqueologia do Saber, a Formação Discursiva (FD) é um gesto analítico que pretende regular a dispersão e construir uma frágil unidade que permita avaliar a raridade dos enunciados (FOUCAULT, 2008). Neste trabalho, então, é preciso pensá-la na modalidade de uma ordenação dos discursos, que organiza modos de dizer sobre objetos e conceitos e que se configura em estratégias de poder, ligadas aos sujeitos.

Na pesquisa realizada no jornal Folha de São Paulo, o que se pode perscrutar foi a presença de 3 FD's organizando e distribuindo os enunciados, que aqui nomeamos: a primeira, uma formação discursiva religiosa; a segunda, uma formação discursiva liberal-meritocrática, e a terceira, uma formação discursiva de defesa da diversidade e de consequente positivação da homossexualidade. Nessas análises iniciais, é importante retomar Orlandi (2008, p.14), que considera: "[...] o discurso é um processo contínuo que não se esgota em uma situação particular. Outras coisas foram ditas antes e outras serão ditas depois. O que temos são sempre pedaços, trajetos, estados do processo discursivo". É o momento de inventariar as FD's.

\subsection{Formação Discursiva Religiosa}

A formação discursiva religiosa presente em algumas notícias que compõe o corpus da Folha de São Paulo relativo à posse do presidente da Câmera de Direitos Humanos e Minorias $(\mathrm{CDHM})$ permite identificar fortemente a área de interesse do presidente. Tal identificação é facilitada ao passo que se conhece o discurso praticado pelo então presidente, Marco Feliciano, anterior e posteriormente a sua posse. O discurso de Feliciano, enunciado a partir da FD religiosa, carrega, ainda a autoridade baseada nos escritos mais fundamentais, na Lei. Assim é que, no dia que antecede sua posse, 6 de março de 2013, o deputado-pastor escreve uma coluna, na sessão Opinião do jornal, intitulada A Ditadura Gay e os Direitos Humanos, em que afirma:

Sobre homossexuais, minha posição é mais tolerante do que se pode imaginar. Como cristão, aprendi no Evangelho que somos todos criaturas de Deus. Nunca me dirigi a nenhum grupo de pessoas com desrespeito. Apenas ensino o que aprendi na Bíblia, que não aprova a relação sexual nem o casamento entre duas pessoas do mesmo sexo. Fora isso, a salvação está ao alcance de todos. Essa é a minha fé - só prego o amor e o perdão. (FELICIANO, 2013)

Observem-se dois movimentos: ao mesmo tempo em que afirma a tolerância para além do senso comum a seu respeito - "mais tolerante do que" -, Feliciano retoma o Evangelho e seus ensinamentos, que funcionam então como avaliadores transcendentais de qualquer discurso sexual ou afetivo. O açambarcamento do enunciado da tolerância realizado pela FD religiosa implica uma assunção daquilo que Maingueneau (2000) chamou de "discurso constituinte", a saber:

Esse termo grego, étimo do latino archivum, apresenta uma polissemia interessante para nossa perspectiva: ligado a arché, "fonte", "princípio", e a partir daí "mandamento", "poder", o archéion é a sede da autoridade, um palácio, por exemplo, um corpo de magistrados, mas também os "arquivos públicos". O archéion associa assim intimamente o trabalho de fundação no e pelo discurso, à determinação de um lugar associado a um corpo de 
enunciadores consagrados, e à elaboração de uma memória. (MAINGUENEAU, 2000, p.7, grifos do autor).

Para o autor francês, seriam justamente prototípicos o discurso religioso, o científico e o filosófico. A principal característica desse discurso religioso tomado como constituinte é seu caráter de fundação das outras discursividades, que lhe garante uma assimetria discursiva. No caso de Feliciano, o que se notará é a repetição dessa assimetria em cada uma de suas aparições discursiva no corpus analisado. Na edição da Folha de São Paulo do dia $1^{\circ}$ de abril de 2013, uma reportagem traz à tona um vídeo datado da mesma semana, em que Marco Feliciano afirma a seus fiéis: "Essa manifestação toda se dá porque, pela primeira vez na história desse Brasil, um pastor cheio de espírito santo conquistou o espaço que até ontem era dominado por Satanás".

Quando se refere à "essa manifestação", Feliciano quer chamar a atenção para aqueles que defendem os direitos das minorias, notadamente genérico-sexuais. Contrapondo-se ao grupo, reafirma sua estratégia discursiva de transformação via discurso constituinte: de um lado, o discurso da verdade e da Lei, que toma o poder de forma legítima. Do outro, o inimigo a ser produzido, "Satanás". A homossexualidade, enunciada como "ditadura gay", seria apenas um discurso a combater, uma série de práticas a perdoar, de acordo com a verdade de uma anunciação divina.

O que se pode descrever é que, para além de posições ideológicas ou de defesa dos direitos humanos, a estratégia adotada pelo pastor-deputado é a de desqualificar os demais discursos a partir da força essencial da FD religiosa. Para construir esse espaço de verdadeiro, seu discurso não é constituído não somente do que agora é por ele dito, mas também pelo o que já foi por ele dito a partir do caráter essencial do discurso religioso. No caso da homossexualidade e como afirmava Foucault (2009), a estratégia é a de criação positiva de uma anormalidade, dessa feita da ordem metafísica: são dos corpos doentes que é preciso recuperar segundo a pastoral neopetencostal. Um embate do campo do direito público republicano, portanto, deve ceder espaço ao a priori fundante da FD religiosa, um discurso de feitos constituintes e devidamente assimétrico.

\section{2 Formação Discursiva Liberal-Meritocrática}

Objeto de discussão e embate entre os discursos que circulam na Folha, tanto a FD religiosa que defende quanto a posição de sujeito que ocupa Marco Feliciano serão contestadas no período pesquisado, por vários setores da sociedade brasileira que podem ocupar a posição de autoria do jornal. Em coluna do dia 7 de abril de 2013, a ombudsman do jornal, Susana Singer, escreve a coluna Santo ou Satanás (SINGER, 2013), em que critica a tática responsiva em relação ao discurso de Feliciano: "é importante reconhecer que a cobertura do caso Feliciano ganhou ares de linchamento. E não há dúvida de que existe na grande imprensa brasileira uma visão estereotipada e preconceituosa dos evangélicos".

Assim, é preciso atentar, no funcionamento discursivo desse "embate", um caráter constitutivo existente entre os discursos religiosos e os discursos liberais: contemporâneos, diametralmente opostos, eles vão se adensando e ganhando identidade apenas no jogo em que se instauram. No caso da FD Liberal-Meritocrática, os discursos terão como objeto as condutas de Feliciano e os conceitos buscarão aproximá-lo ou apartá-lo da ordem da ética política, da liberdade democrática e do mérito para assumir a presidência da CDHM. 
No intuito de se contrapor ao transcendentalismo de Feliciano, da perspectiva dessa FD Liberal-Democrática, a Folha publicará dezenas de artigos, das mais variadas ordens e dos mais diferentes autores, apontando - na forma de produção de objetos - para os problemas na conduta pessoal e política de Feliciano, que o impediriam de assumir a presidência da CDHM. Esses enunciados configuram uma FD "liberal-democrática", pois, são construídos por um caráter de suposta isonomia - a FD cria efeito de não-preconceituosa, parte de princípios de direito republicano e constitucional - e pelo exercício de produzir uma crise de legitimação nos discursos de Feliciano, tanto do presente da enunciação quanto do intertexto e da memória.

Dentre as reportagens, alguns títulos são bastante significativos desse caráter, a saber:

Eleição de pastor para comando de comissão pode ser revista, diz presidente da Câmara - na edição de 9 de março (09 mar.2013).

Líderes questionam PSC sobre permanência de pastor em comissão - na edição de 12 de março (DECAT, 2013a)

Deputados questionam no STF eleição de Feliciano em comissão da Câmara - na edição de 12 de março (NALON, 2013a)

Deputados criam grupo contra pastor na presidência de comissão - na edição de 11 de março (DEPUTADOS..., 2013)

PSC mantém pastor na presidência da Comissão de Direitos Humanos - na edição de 12 de março (NALON, 2013b)

PSOL avalia ir à Corregedoria da Câmara contra Feliciano - na edição de 14 de março (DECAT, 2013b)

Durante o período analisado, além disso, 7 capas da Folha de São Paulo trarão chamada relativa à "polêmica na CDHM", sendo que ao menos 3 delas colocam a conduta do deputadopastor. Já no dia 6 de março, a chamada instala o clima de distensão: " Partido escolhe pastor polêmico para comissão sobre minorias". A polêmica, como se verá a partir de então, diz respeito: à religiosidade neopetencostal; aos problemas éticos que envolvem Feliciano e que o desqualificam como homem público. Se a primeira polêmica pode ser resolvida, ainda que de forma restrita, via FD religiosa, a segunda das polêmicas merecerá discursos de atenção policialesca, que aparece nas seguintes chamadas de capa: "Eleito para a comissão de direitos humanos, pastor é alvo de ação" (capa do dia 8 de março, que apresenta denúncias contra o deputado-pastor); "Pastor Feliciano emprega cinco colegas que não dão expediente" (capa do dia 13 de março, que descreve o problema, relacionando-o à posição de sujeito de "pastor" e não de deputado).

A partir de tais enunciados, fica evidente que a postura de Marco Feliciano requer que se enuncie críticas, mas somente se inscritas numa posição mais ética e justificada, pautada nas leis e no exercício democrático. Contra a força da FD religiosa, o que se propõe é deixar clara a diferença entre um direito afetivo-sexual "legítimo", de acordo com a ordem do público, e uma ausência de medidas, pautada apenas na religiosidade - e na falta de ética - de Feliciano e o discurso que defende. 
Finalmente, a Folha pode justificar suas críticas pelos próprios dados de seus leitores, que apóiam maciçamente os direitos humanos das minorias sexuais e se colocam contrariamente aos discursos de Feliciano. É sobre o discurso desses direitos que falará a sessão a seguir.

\subsection{Formação Discursiva de Defesa da "Diversidade"}

Como é fácil inferir, também é possível perceber a partir do corpus analisado a sustentação de uma formação discursiva da "diversidade", relacionada, neste trabalho, à positivação de minorias genérico-sexuais, onde se destacam a homossexualidade e a homoafetividade. Neste sentido, na Folha de São Paulo, o presidente da comissão dos direitos humanos é anunciado como o pastor que prega e combate de projeto a homofobia, produzindo um discurso de resistência, cujo funcionamento cabe investigar.

Além da incapacidade e da falta de ética suscitada nos discursos da FD liberal-meritocrática, a FD da diversidade que se postula permite entender como se organizam, no jornal, os vários descontentamentos que defendem que, para assumir um cargo de presidência de direitos humanos, é inconcebível que Marco Feliciano mantenha uma postura preconceituosa e negativa, baseada na FD religiosa, em relação à homossexualidade e à etnia. Alguns títulos chamam, novamente, a atenção:

Pastor diz que não recuará e prega combate a projeto sobre homofobia - edição de 12 de março (COLON, 2013). Neste enunciado, pode-se observar a divisão entre uma posição de sujeito, da ordem religiosa - o "pastor" - , que se contrapõe à ética democrática e pública, de um "projeto" [de lei].

Deputado Marco Feliciano nega ser racista e homofóbico - edição de 11 de março (DEPUTADO,2013). Neste enunciado, a Folha recorre - como se verá na seção seguinte deste trabalho - às pregações de Feliciano, que se utilizam no intertexto bíblico para construir enunciados que negativizam tanto etnia quanto práticas não-heteronormativas.

Grupo faz protesto em culto do pastor Feliciano em Franca (SP) - edição de 11 de março (GRUPO, 2013). Novamente, o enunciado recorre à cisão entre o discurso da legalidade republicana e democrática e a FD religiosa: o "grupo" anunciado é o dos manifestantes ligados sobretudo ao PSOL e a políticas de gênero e etnia, que "denuncia" a estratégia "anticonstitucional" da FD de onde enuncia Feliciano. Note-se, ainda, a separação entre "protesto" e "culto", e a retomada do designador "pastor".

Manifestação contra pastor reúne 600 pessoas e fecha duas faixas da Avenida Paulista edição de 9 de março (MANIFESTAÇÃO, 2013). Mais uma vez, o enunciado cinde "manifestantes", do discurso da FD liberal-meritocrática, e o "pastor", da FD religiosa. Acrescente-se aí o uso de expressões para quantificar a presença de manifestantes, que apontam um discurso que tende a criar o "isolamento" do pastor e dos discursos da FD religiosa em relação à organização maciça da população contrária.

Além desses títulos, é importante destacar, como discurso de resistência de produção positiva da homossexualidade, o texto Cinismo cruel, que aparece na edição de 6 março, contrapondose a texto já mencionado (FELICIANO, 2013). Escrito também para a coluna Opinião, é de autoria do deputado federal Jean Wyllys, PSOL, que tem se destacado por seu discurso de defesa dos direitos das minorias, notadamente genérico-sexuais, e pelos embates que tem travado com os discursos relacionados à FD religiosa da bancada evangélica da Câmara. 
A coluna de Wyllis (2013), também deputado federal, mas defensor dos discursos GLBTT na Câmara, evidencia a preocupação em relação a possível posse de Feliciano como presidente da CDHM. O autor faz questão de salientar a inexistência de qualquer preconceito religioso em relação ao pastor - o que faz, de outra posição, Feliciano (2013) - e justifica a sua oposição ao afirmar que o deputado "é um inimigo público e declarado de minorias estigmatizadas e tem um discurso público que estimula a violação da dignidade humana desses grupos". Inicialmente, é preciso destacar, no texto, o uso de expressões como "público" e de "dignidade humana", relacionado ao interdiscurso dos direitos humanos, da legalidade e da ordem democrática. Essa presença do interdiscurso fornecerá, para Wyllys, a estratégia fundamental de destituição de legitimidade dos discursos de Feliciano.

Wyllys problematiza a postura do deputado e apresenta preocupação ao indagar:

Como pode presidir uma comissão de direitos humanos e minorias um deputado que disse que o problema da África negra é "espiritual" porque "os africanos descendem de um ancestral amaldiçoado por Noé", revivendo uma interpretação distorcida e racista da Bíblia, que já foi usada no passado para justificar a escravidão dos negros?

Como pode presidir uma comissão de direitos humanos e minorias um deputado que se referiu à Aids como "o câncer gay"? Um deputado que defende um projeto de lei para obrigar o Conselho Federal de Psicologia a aceitar supostas "terapias de reversão da homossexualidade" anticientíficas e baseadas em preconceitos. (WYLLYS, 2013).

No discurso de Wyllys, a FD da diversidade permite açambarcar uma teleologia, com tintas iluministas: entre o mundo arcaico da crença e da "distorção", e um universo "científico" e "legal", a escolha parece bastante simples. É preciso sair das trevas da fé cega e, por meio do discurso da FD, levar um "conhecimento verdadeiro" sobre as questões de sexo, gênero e etnia. ${ }^{1}$

Após apresentar seu descontentamento e indignação com a situação de ansiedade precedente à eleição da presidência da CDHM, Wyllys justifica a elaboração de seu texto: "é isso que estou fazendo, tentando representar aqueles que, como eu, sempre receberam mais insultos e porradas que direitos e estima! Saibam que não estão sozinhos! Luta que segue!’.

Ao analisar tal texto, publicado na Folha percebe-se que, além das indagações, existe no discurso de Wyllys uma série de críticas sobre a conduta de Marco Feliciano, sobretudo relação à homossexualidade. O embate, no entanto, se configura também pelos discursos responsivos do "pastor", negando ser racista e homofóbico Assim, em 11 de março de 2013, com o enunciado de Deputado Marco Feliciano nega ser racista e homofóbico, a imprensa online Folha de São Paulo, expõe a defesa de Marco Feliciano sobre as principais críticas que recebe desde que seu nome foi sugerido e que se intensificam na imprensa:

Em relação à frase considerada homofóbica, disse ter sido mal interpretado. "Julgar uma pessoa de 40 anos por 140 caracteres [limite para cada postagem no Twitter] citados numa rede social, sem contexto, isso é uma violação dos direitos humanos.". (DEPUTADO, 2013).

\footnotetext{
${ }^{1}$ Certamente, as opiniões de Feliciano são dificilmente defensáveis e carecem de argumentos ligados ao mundo da objetividade e da imanência. No entanto, este trabalho ocupa-se não de uma tratamento valorativo, mas de investigar a produção de discursos.
} 
Leia-se: Feliciano, no recorte, tende a negativizar os discursos online, o "Twitter" e incorporar sua crítica a um critério etário - ele, com mais de 40 anos, enquanto que hpa um outro, que pode ser mais jovem - e a própria imprensa, que pode ter feito "má-interpretação". A Folha, por sua vez, usa das estratégias do discurso citado para criar a objetividade e, principalmente, para esclarecer uma posição de sujeito, com a qual tende a discordar.

A posição da Folha, ao que parece, justifica-se pela dubiedade dos enunciados de Marco Feliciano, que partem da FD religiosa - afinal, ele é um pastor eleito por seus pares - mas que devem levar em consideração a ordem da legalidade, da FD liberal-meritocrática. Dessa perspectiva, nos enunciados supramencionados, pode-se identificar uma dualidade discursiva: ao passo que o presidente não aceita a nominação de racista e homobófico para si, tende a afirmar um combate de projeto sobre homofobia. Tal dualidade percebida através de análise dos dois enunciados destacados se fortalece ao passo que outras notícias são integradas ao corpus de análise.

Diante disso e na configuração dos saberes sobre sexualidade e gênero contemporânea, conforme a seção dois deste trabalho, é mister também perceber o papel político da Folha. Ainda que com acusações de linchamento, o que o jornal oferece é uma posição bastante explícita, ligada às expectativas de seus leitores e a pretensa ideia de um Estado de direito democrático e laico que é previsto pela Constituição do Brasil.

\section{A MEMÓRIA DO DISCURSO}

Para a AD, como se viu até aqui, o discurso é o locus dos embates entre poder e linguagem. Tais discursos são constituídos na modalidade do interdiscurso, entendido como "[...] o conjunto do dizível, histórica e linguisticamente definido..." (ORLANDI, 1997, p. 89). Assim, todo enunciado possível, seguindo a esteira de Foucault (2008) é um acontecimento da ordem do poder, uma função que tem por possibilidade articular a dispersão dos discursos e organizar um sistema de produção de objetos, conceitos e formas de enunciação que se estabelecem a partir do já-dito, do arquivo, inaugurando novos enunciados, na modalidade do acontecimento.

O enunciado foucauldiano, portanto, funciona numa tensão entre a repetição e a transformação, entre as normatizações de um solo discursivo e a contingência de outras enunciações. A memória discursiva, da ordem do interdiscurso, estabelece uma constante negociação de sentidos e implica os leitores na produção de seus efeitos. Quando se fala, em AD, de "memória", então, concorda-se com Possenti (2008), para quem a "memória discursiva" é sempre social e só se constitui em circulações de discursos sociais, e nunca pode ser pensada de forma estanque ou subjetivista. Adiante, Possenti (2008, p.23, grifos nossos) estabelece a distinção entre "saber" e "memória":

[...] um saber se caracterizaria por um conjunto de restrições semânticas; (...) a memória se caracterizaria por um conjunto de representações de acontecimentos (eventos, principalmente, mas também enunciados, em sua materialidade mesma, ou seja, de enunciados enquanto eventos.).

No caso da presente pesquisa, é preciso notar que o discurso jornalístico se constitui na dispersão dos discursos, no interdiscurso, a partir de processos de re-atualização de enunciados, que pode ser vista sob a ótica da "memória". O funcionamento do discurso jornalístico exige que se retome a interdiscursividade e a intertextualidade, produzindo uma 
relação entre novos saberes e memórias, entre já ditos e enunciados atualizados. Não obstante a exigência de objetividade, o jornalismo se caracteriza por uma disciplinarização dos regimes da memória e de uma retomada estratégica dos discursos.

Tratando-se de interdiscurso e de intertexto, metodologicamente adota-se aqui a proposta de Fiorin (2006), para quem o "interdiscurso" é uma condição de todo enunciado, enquanto relação de memória e dispersão entre os discursos, enquanto a intertextualidade exige a materialização nos enunciados, seja como citação, alusão ou estilização. Para tratar dos processos de interdiscursividade e memória, à luz dessa diferenciação, este trabalho se utilizará de um conceito tomado de Maingueneau (2006) apud Miranda (2010) e considerado por esse autor como típico do discurso jornalístico, por sua relação com a memória, o interdiscurso e a intertextualidade: o destacamento dos enunciados, criado num processo de sobreasseveração. A sobreasseveração de um enunciado caracteriza-se quando acontece uma espécie de "encenação" das enunciações anteriores. De acordo com Miranda (2010, p.134) o funcionamento do enunciado sobreasseverados exige deles certas condições:

[...] ser relativamente breve; estar numa posição relevante no texto, de modo que lhe é atribuído o estatuto de um condensado semântico, de produto de uma espécie de sedimentação da realização do discurso; ter uma temática relacionada ao intuito de gênero de discurso, constituindo uma tomada de posição no interior de um conflito de valores; implicar um tipo de "amplificação" da figura do enunciador, manifestada por um ethos apropriado. Para o teórico, "a citação está inscrita no próprio funcionamento da máquina midiática”, pois há todo um trabalho, feito pela instância de produção midiática, de destacamento de enunciados de textos para convertêlos em citações.

No corpus da pesquisa, 16 de março de 2013, no editorial Sem condições. Note-se, inicialmente, que o "editorial" deve ser lido segundo a ordem da "autoria institucional", que "serve para produzir a identidade genérica do editorial o fato de ele possuir uma autoria institucional assumida internamente pela própria empresa e pelo veículo de comunicação onde é publicado' " (ALVES FILHO, 2006, p.83). Tomem-se, inicialmente, dois recortes do Editorial:

O deputado se notabilizou por afirmar que "africanos descendem de ancestral amaldiçoado por Noé", o que seria "um fato". Considera também que, depois da união civil entre homossexuais, virá a extinção das palavras "pai" e "mãe".

[...]Política, entretanto, implica diálogo e mediação. As declarações de Marco Feliciano não se pautam pela civilidade, nem mesmo por um mínimo cabedal de instrução. (SEM, 2013)

Em outro momento, tem-se o discurso destacado na "coluna de opinião". Diferente do que acontecia com o "editorial", a "coluna de opinião" tem relações discursivas com a instituição a empresa jornalística -, mas " destas [editoriais] diferem pelo caráter externo da autoria: articulistas são, em geral, representantes de prestígio social dos diversos segmentos profissionais dos grupos sociais" ALVES FILHO, 2006, p.83), o que garante uma posição de sujeito diferente. A partir dessa característica, leia-se o recorte da coluna de Ricardo Mendonça (MENDONÇA, 2013), publicada em 2 de abril e intitulada Análise: Descalibrado no jogo interno, Feliciano pode morrer pela boca. O enunciado é o seguinte: "Na sexta-feira 
passada, Feliciano disse que, antes de sua chegada, a Comissão de Direitos Humanos era 'controlada por Satanás ' ".

Finalmente, é preciso trazer à tona os recortes do texto Feliciano volta a afirmar que africanos são amaldiçoados, publicado em 5 de abril (NALON; VALENTE, 2013)

Em 2011, ele escreveu que "a podridão dos sentimentos dos homoafetivos leva ao ódio, ao crime, à rejeição". [...]

"Citando a Bíblia [...], africanos descendem de Cão [ou Cam], filho de Noé. $\mathrm{E}$, como cristãos, cremos em bênçãos e, portanto, não podemos ignorar as maldições", afirmou, na peça protocolada em seu nome pelo advogado Rafael Novaes da Silva. [...]

A defesa disse ainda que há uma forma de "curar a maldição", entregando "os seus caminhos ao Senhor". "Tem ocorrido isso no continente africano. Milhares de africanos têm devotado sua vida a Deus e por isso o peso da maldição tem sido retirado", diz o texto. [...]

Ao STF afirmou que suas manifestações no Twitter estão "ligadas ao exercício de seu mandato".

Nos três blocos de citação, de três textos distintos publicados no recorte temporal que é parte do corpus, fica evidente o funcionamento do discurso da Folha e sua remissão à memória. Assim, diante de uma polêmica discursiva, o que a Folha produz é uma série de enunciados de citação, que, destacados de seu tempo e de seu espaço enunciativo, criam o que Maingueneau postal como sobreasseveração.

O que interessa nota é que os enunciados sobreasseverados, destacados, são: parte da memória discursiva, já que a série temporal é começa em 2011, produzem um acontecimento, porque re-enunciam, com novas estratégias, objetos, conceitos e posições, os enunciados de Feliciano; recorrem à separação, novamente, entre legalidade e religião.

Retome-se a separação "legal" x "religioso". Ao destacar os discursos de Feliciano e produzir a sobreasseveração, a Folha e seus autores tendem a criar uma oposição bastante marcada. Assim, no Editorial, cuja marca é a posição do veículo, a citação de Feliciano relativa aos negros e à maldição é seguida da "política" e da "civilidade", duas questões que são interditadas pela posição de sujeito ocupada pelo pastor.

Isso ocorre nos outros recortes: em Mendonça (2013), a chegada à CDHM, na ordem da legalidade, é contraposta ao espaço discursivo da religião, onde Feliciano teria cometido discurso: "Satanás" é quem controlaria as minorias sexuais. Em Nalon e Valente (2013), por fim, o aparecimento da citação é mais marcado e os qualificadores abundam e tanto homossexuais quanto negros são "condenados": à exclusão, a rejeição, ao crime. Para além dos exageros da FD religiosa de onde enuncia, cabe notar o mecanismo de sobreasseveração da coluna: destacam-se os enunciados de Feliciano, construindo uma posição discursiva marcada, da qual se deve discordar. Por fim, traz-se à tona a política liberal - a FD liberaldemocrática - e um estranhamento em relação à decisão do STF - "Ao STF afirmou que suas manifestações no Twitter estão 'ligadas ao exercício de seu mandato'". 
O que os mecanismos de sobreasseveração fazem, como se viu, é criar um efeito de objetividade para os discursos de Feliciano - afinal, foi ele mesmo que produziu tais enunciados - e, deslocando-os em seu espaço-tempo, criar uma estratégia constante de uso da memória discursiva dos leitores da Folha. Assim é que o jornal, politicamente engajado, incita seus leitores a contrapor liberdade e norma religiosidade, diversidade e unicidade, heteronormatividade transcendental e multiplicidade sexual afetiva, ordem republicana e constitucional e religiosidade. Ao que parece, a Folha parte da ideia foucauldiana de que o discurso é aquilo pelo que se luta e são os embates micro-discursivos e diários que configuram formas mais humanizadas, diversas e éticas de existência.

\section{CONSIDERAÇÕES FINAIS}

No que tange às conclusões da pesquisa, aponta-se para um regime de dizer bastante marcado pelo embate entre a FD Religiosa, representada pelo pastor-deputado Marco Feliciano, e as FD's Liberal-meritocrática e da Diversidade, que tangenciam discursos republicanos, libertários e da diferença. Fundamentalmente, o que se observa é que as FD's têm sua produção calcada na deslegitimação recíproca e ocupam espaços midiáticos similares e até mesmo a mesma materialidade linguística; seus discursos, porém, partem de táticas específicas, sobreasserverando os enunciados de acordo com os efeitos de sentido que lhes são peculiares.

A posição combativa da Folha, ao que parece, justifica-se pela dubiedade dos enunciados de Marco Feliciano, que partem da FD religiosa - afinal, ele é um pastor eleito por seus pares mas que devem levar em consideração a ordem da legalidade, da FD liberal-meritocrática. Dessa perspectiva, nos enunciados supramencionados, pode-se identificar uma dualidade discursiva: ao passo que o presidente não aceita a nominação de racista e homobófico para si, tende a afirmar um combate de projeto sobre homofobia e reafirmar posições racistas. Ainda que com acusações de linchamento, o que o jornal oferece é uma posição bastante explícita, ligada às expectativas de seus leitores e a pretensa ideia de um Estado de direito democrático e laico que é previsto pela Constituição do Brasil.

\section{REFERÊNCIAS}

ALVES FILHO, F. A autoria institucional nos editoriais de jornais. Alfa, São Paulo, v. 50, n.1, p. 77-89, 2006.

BUTLER, J. Problemas de gênero: feminismo e subversão da identidade. Trad. Renato Aguiar. Rio de Janeiro: Civilização Brasileira, 2003.

BUTTURI JUNIOR, A. A passividade e o fantasma: o discurso monossexual no Brasil. 2012, 239f. Tese (Doutorado) - Programa de Pós-Graduação em Linguística. Universidade Federal de Santa Catarina, 2012.

COSTA, J. F. A face e o verso: estudos sobre homoerotismo II. São Paulo: Escuta, 1995.

FOUCAULT, M. A arqueologia do saber. 7. ed. Trad. Luiz Felipe Baeta Neves. Rio de Janeiro: Forense Universitária, 2008.

. História da sexualidade I: a vontade de saber. 19. ed. Trad. Maria Thereza Albuquerque e J. A. Guilhon Albuquerque. Rio de Janeiro: Graal, 2009. 
. Não ao sexo rei. In: . Microfisica do poder. 11. ed. Trad. Roberto Machado. Rio de Janeiro: Graal, 1993. p. 229-242.

MAINGUENEAU, D. Analisando discursos constituintes. Revista do GELNE, Fortaleza, v.2, n.2, p.167-178, 2000.

MIRANDA, M. A. Enunciados destacados, discurso direto e efeitos de patemização na mídia televisiva. Revista Virtual de Letras, São Paulo, v.2, n.2, p. 133-144, 2010. Disponível em: $<$ http://www.revlet.com.br/artigos/57.pdf>. Acesso em: 20 mar. 2013.

ORLANDI, E. P. As formas do silêncio no movimento dos sentidos. Campinas: Unicamp, 1997. 2008 .

Discurso e texto: formulação e circulação dos sentidos. 3. ed. Campinas: SP. Pontes,

POSSENTI, S. Slogans que se retomam. In: TASSO, I. (Org.). Estudos do texto e do discurso: interfaces entre língua(gens), identidade e memória. São Carlos, SP: Claraluz, 2008. p. 17-28.

\section{WEBGRAFIA}

COLON, L. Pastor diz que não recuará e prega combate a projeto sobre homofobia. Folha de São Paulo, São Paulo, 12 mar. 2013. Disponível em:

$<$ http://www1.folha.uol.com.br/poder/1244653-pastor-defende-combate-a-projeto-de-lei-quecriminaliza-a-homofobia.shtml>. Acesso em: 12 mar.2013.

DECAT, E. Líderes questionam PSC sobre permanência de pastor em comissão. Folha de São Paulo, São Paulo, 12 mar. 2013a. Disponível em:

$<$ http://www1.folha.uol.com.br/poder/1245082-lideres-questionam-psc-sobre-permanenciade-pastor-para-comissao.shtml>. Acesso em: 12 mar.2013.

DECAT, E. PSOL avalia ir à Corregedoria da Câmara contra Feliciano. Folha de São Paulo, São Paulo, 14 mar. 2013b. Disponível em: <http://www1.folha.uol.com.br/poder/1246157psol-avalia-ir-a-corregedoria-da-camara-contra-feliciano.shtml $>$. Acesso em: 14 mar.2013.

DEPUTADO Marco Feliciano nega ser racista e homofóbico. Folha de São Paulo, São Paulo, 11 mar. 2013. Disponível em:

$<$ http://www1.folha.uol.com.br/cotidiano/ribeiraopreto/1243979-deputado-marco-felicianonega-ser-racista-e-homofobico.shtml>. Acesso em: 11 mar.2013.

DEPUTADOS criam grupo contra pastor na presidência de comissão. Folha de São Paulo, São Paulo, 11 mar. 2013. Disponível em: <http://www1.folha.uol.com.br/poder/1244269deputados-montam-grupo-contra-escolha-de-pastor-para-presidencia-de-comissao.shtml $>$. Acesso em: 11 mar.2013.

FELICIANO, M. A ditadura gay e os direitos humanos. Folha de São Paulo, São Paulo, 6 mar. 2013. Disponível em: < http://www1.folha.uol.com.br/opiniao/1241323-marco-felicianoditadura-gay-e-direitos-humanos.shtml >. Acesso em: 6 mar. 2013.

GRUPO faz protesto em culto do pastor Feliciano em Franca (SP). Folha de São Paulo, São Paulo, 11 mar. 2013. Disponível em:

$<\mathrm{http}$ //www1.folha.uol.com.br/cotidiano/ribeiraopreto/1244225-grupo-faz-protesto-em-cultodo-pastor-feliciano-em-franca-sp.shtml>. Acesso em: 11 mar.2013.

MANIFESTAÇÃO contra pastor reúne 600 pessoas e fecha duas faixas da Avenida Paulista. Folha de São Paulo, São Paulo, 09 mar. 2013. Disponível em: < 
http://www1.folha.uol.com.br/poder/1243748-manifestacao-contra-pastor-reune-600-pessoase-fecha-duas-faixas-da-avenida-paulista.shtml >. Acesso em: 09 mar.2013.

MENDONÇA, R. Análise: descalibrado no jogo interno, Feliciano pode morrer pela boca. Folha de São Paulo, São Paulo, 2 abr. 2013. Disponível em:< http://www 1.folha.uol.com.br/poder/1255786-analise-descalibrado-no-jogo-interno-felicianopode-morrer-pela-boca.shtml >. Acesso em: 2 abr. 2013.

NALON, T. Deputados questionam no STF eleição de Feliciano em comissão da Câmara. Folha de São Paulo, São Paulo, 12 mar. 2013a. Disponível em:

$<$ http://www1.folha.uol.com.br/poder/1244846-deputados-questionam-no-stf-eleicao-defeliciano-em-comissao-da-camara.shtml>. Acesso em: 12 mar.2013.

NALON, T. PSC mantém pastor na presidência da Comissão de Direitos Humanos. Folha de São Paulo, São Paulo, 12 mar. 2013b. Disponível em:

$<$ http://www1.folha.uol.com.br/poder/1245097-psc-mantem-pastor-na-presidencia-dacomissao-de-direitos-humanos.shtml>. Acesso em: 12 mar.2013.

NALON, T.; VALENTE, R. Feliciano volta a afirmar que africanos são amaldiçoados. Folha de São Paulo, São Paulo, 5 abr. 2013. Disponível em: <

http://www1.folha.uol.com.br/poder/1257600-feliciano-volta-a-afirmar-que-africanos-saoamaldicoados.shtml>. Acesso em: 5 abr. 2013.

SÁ, D. Eleição de pastor para comando de comissão pode ser revista, diz presidente da Câmara. Folha de São Paulo, São Paulo, 09 mar. 2013. Disponível em:

$<$ http://www1.folha.uol.com.br/poder/1243602-eleicao-de-pastor-para-comando-de-comissaopode-ser-revista-diz-presidente-da-camara.shtml>. Acesso em: 09 mar.2013.

SEM condições. Folha de São Paulo, São Paulo, 16 mar. 2013. Disponível em: $<$ http://www1.folha.uol.com.br/opiniao/1247331-editorial-sem-condicoes.shtml>. Acesso em: 16 mar.2013.

SINGER, S. Santo ou satanás. Folha de São Paulo, São Paulo, 7 abr. 2013. Disponível em: $<$ http://www1.folha.uol.com.br/colunas/suzanasinger/1258584-santo-ou-satanas.shtml>. Acesso em 7 abr. 2013.

WYLLYS, J. Cinismo cruel. Folha de São Paulo, São Paulo, 06 mar. 2013. Disponível em: http://www1.folha.uol.com.br/opiniao/1241330-jean-wyllys-cinismo-cruel.shtml>. Acesso em: 06 mar.2013. 